\title{
The Relationship between Insulin Resistance and Type II Ketosis in Dairy Cows
}

\author{
Zhang Cuiyu, Zhao Chang, Zhang Jiang, Xia Cheng \& Zhang Hong You
}

\begin{abstract}
Background: Cows in perinatal period are prone to ketosis, characterized by increased ketone bodies and decreased blood sugar. Study found that cows with type II ketosis had higher blood glucose levels. This type of ketosis exhibits insulin resistance and impaired glucose tolerance that are similar to type 2 diabetes. The purpose of this study was to investigate the role of insulin resistance(IR) in type II ketosis in dairy cows.

Materials, Methods \& Results: In one intensive cattle farm, eight cows with ketosis and eight healthy cows that were 1421 days postpartum were selected. The plasma of experimental dairy cows was collected and tested for the concentration of glucose concentration. Glucose tolerance of blood glucose levels in 120 min was used as the cut-off point to divide the dairy cows into three groups: the abnormal glucose tolerance ketosis group (TH), the normal glucose tolerance ketosis (TL), and the healthy control group. Simultaneously, the indexes of plasma liver function, oxidative stress, and insulin resistance were detected. The results showed that after intravenous glucose injection, there was no significant difference in blood glucose concentration between the TL and control group, while the blood glucose levels in the TH group were always higher than in the other two groups. The insulin sensitivity index (RQUICKI) value was significantly lower in the $\mathrm{TH}$ group than in the other two groups. Liver function abnormalities in the TH group were more severe than in the TL and control group. Oxidative stress was higher in the TH group than in the TL and control groups.

Discussion: Postpartum dairy cows, with high lactation, consume large amounts of sugar, resulting in a lower blood sugar, and the postnatal dry matter intake peak is later than the peak lactation, which further decreases blood sugar and leads to a negative energy balance in cows. Such ketosis is associated with NEB caused by hypoglycemia, However, a survey of blood glucose concentration in cows with ketosis shows that ketosis can still occur in cows with high blood sugar levels. The pathogenesis of hyperglycemic ketosis is still unclear. Insulin Resistance (IR) refers to tissue sensitivity to insulin decreases, compensatory Islet beta cells secreting insulin thus producing hyperinsulinemia. AST is a typical indicator of liver damage, plasma AST levels in Group TH were significantly higher than the other two groups. The RQUICKI is a key indicator determining whether the body has developed insulin resistance. the plasma insulin sensitivity index of group TH was significantly lower than Group TL and C. BHBA levels in serum is the gold standard for the diagnosis of cow ketosis. The concentration of NEFA and BHBA in the blood is a sign of negative energy balance. The concentration of BHBA and NEFA in the TH group was significantly higher than in the group $\mathrm{C}$, and the concentration of BHBA was higher than the critical value of ketosis. SOD is a metal antioxidant enzyme and its level are key indicators in measuring the removal of oxidizing substances. T-AOC is a measuring indicator for total antioxidant function. The reduction of SOD and T-AOC concentrations in the TH group indicated that the antioxidant capacity of ketone cows with abnormal glucose tolerance was reduced. The above results show that the TH group is severely impaired in liver function, and has a disorder of glucose metabolism, abnormal glucose tolerance and hyperinsulinemi, which also have severe IR. Moreover, the antioxidant capacity of the TH cows with ketosis declined, the body was in a state of oxidative stress. Thus, the occurrence of ketosis in some cows is related to a glucose utilization disorder caused by insulin resistance, and abnormal liver function and oxidative stress are the causes of insulin resistance.
\end{abstract}

Keywords: hyperglycemia, insulin resistance, liver function, oxidative stress, type II ketosis. 


\section{INTRODUCTION}

A negative energy balance caused by hypoglycemia in cows is the main cause of ketosis [14,26]. However, there is also a class of ketosis, in which the blood glucose concentration of the diseased cow does not decrease or even exceeds the normal level. Type II diabetes is closely related to insulin resistance and most patients with type II diabetes are overweight or obese [11]. Cows with hyperglycemia ketosis show insulin resistance and glucose tolerance which is similar to those of type II diabetes, therefore it was named type II ketosis $[1,17]$.

IR is the pathogenic factor of diseases such as diabetes and obesity [4], and its notable features include hyperinsulinism, abnormal glucose tolerance, and type II diabetes. The normal blood glucose insulin clamp technique is an international gold standard method for determining IR [22]. However, it is not suitable for the detection of large samples because it is time-consuming and is expensive [2,29]. Oral glucose tolerance test, the use of blood insulin levels to assess the body's IR level, is widely used at home and abroad. The intravenous glucose tolerance test (IVGTT) is a more reliable trial to measure pancreatic -cell function, which reflects laterally the sensitivity of insulin against the target cell and the reaction rate of glucose metabolism involved [16]. Holtenius used a high accuracy, widely used in clinical method of calculating the RQUICKI to determine the extent of IR [18]. Abnormal glucose tolerance is a necessary stage in the development of type II diabetes. If glucose tolerance is abnormal, insulin resistance will appear in the body [8]. The aim of the study was to research the role of IR in type II ketosis in dairy cows.

\section{MATERIALS AND METHODS}

\section{Test animals and groups}

In an intensive dairy farm, eight cows with ketosis 14-24 days after delivery were selected by the ketone powder method combined with a blood ketone instrument. Among them, four were in good condition, four were in a normal condition, and another eight healthy cows were selected as the control group. Blood samples of the test cows were collected to test the blood glucose level. According to the blood glucose level $2 \mathrm{~h}$ after intravenous glucose, the dairy cows were divided into three groups: the abnormal glucose tolerance ketosis (HT) group, the normal glucose tolerance ketosis (LT) group, and healthy control group (Group C).
The selected animals received a fasting jugular vein injection of $50 \%$ glucose solution. Blood was taken from the tail vein at $15 \mathrm{~min}$ before the injection and 0 , 15, 30, 60, 90, and $120 \mathrm{~min}$ after the injection. Heparin anticoagulation and blood samples were placed in a test tube and centrifuged at $903 \times g$ for $10 \mathrm{~min}$, the resulting plasma was stored at $-80^{\circ} \mathrm{C}$ until tested.

\section{Main test items}

$\beta$-Hydroxybutyrate (BHBA ELISA kit) ${ }^{1}$, blood glucose (GLU ELISA kit) ${ }^{2}$, aminotransferase (ALT ELISA kit) ${ }^{2}$, glutamic oxalacetic transaminase (AST ELISA $\mathrm{kit}^{2}$ albumin (ALB ELISA kit) ${ }^{2}$. Glucagon (GC ELISA kit) ${ }^{3}$, total antioxidant capacity (T-AOC ELISA kit) ${ }^{3}$, total superoxide dismutase (T-SOD ELISA kit) ${ }^{3}$, malondialdehyde (MDA ELISA kit) ${ }^{3}$, Insulin (INS ELISA kit) ${ }^{3}$, Free fatty acid (NEFA ELISA kit) ${ }^{4}$. adiponectin (ADP ELISA kit) ${ }^{5}$. These indicators measured by Hitachi 7170 automatic biochemical analyzer ${ }^{6}$ or $722 \mathrm{~N}$ visible spectrophotometer ${ }^{7}$, DG5033A micro plate reader ${ }^{8}$.

Insulin sensitivity index (RQUICKI):

RQUICKI $=1 /[\log \mathrm{G} 0+\log \mathrm{I} 0+\log \mathrm{FFA} 0])$

\section{Data processing}

The experimental data were analyzed by SPSS17.0 software, using the single factor variance for statistical analysis, and the results are expressed as the mean \pm standard deviation.

\section{RESULTS}

The condition of experimental cow liver function

As shown in Table 1, three groups of plasma ALT levels were not significantly different at all timepoints; in the glucose tolerance test, plasma AST levels in Group TH were significantly higher than the other two groups. Group TL was significantly higher than Group C. At 0-90 min, the plasma ALB concentration in the TH group was significantly lower than the $\mathrm{C}$ group (Table 1 ).

The above results indicate that in the plasma of the TH group, hepatic enzymes were increased and protein synthesized by the liver was also decreased. There were significant differences in liver function indicators between the three groups, indicating that ketosis cows, with abnormal glucose tolerance, were severely impaired by liver function. The ketosis cows with normal glucose tolerance had less liver damage and the differences between the TL group and C group were smaller than that of the $\mathrm{TH}$ group and $\mathrm{C}$ group 
Table 1. Changes of liver function indices of dairy cows with ketosis during glucose tolerance test.

\begin{tabular}{cccccccc}
\hline \multirow{2}{*}{ Parameter } & Group & \multicolumn{7}{c}{ Administration of Glucose (Min) } \\
\cline { 3 - 8 } & & -15 & 0 & 15 & 30 & 60 & 90 \\
\hline \multirow{2}{*}{ ALT } & TH & $25.25 \pm 6.84$ & $22.25 \pm 5.79$ & $23.50 \pm 5.74$ & $23.75 \pm 4.92$ & $23.75 \pm 5.56$ & $23.50 \pm 5.74$ \\
& TL & $24.25 \pm 2.22$ & $24.00 \pm 2.71$ & $24.75 \pm 2.87$ & $24.75 \pm 2.87$ & $24.75 \pm 2.50$ & $22.25 \pm 4.03$ \\
& C & $26.25 \pm 6.75$ & $25.13 \pm 6.24$ & $26.25 \pm 6.34$ & $26.50 \pm 6.36$ & $26.75 \pm 6.45$ & $25.37 \pm 5.73$ \\
\hline \multirow{2}{*}{ AST } & TH & $216.75 \pm 12.68^{\mathrm{A}}$ & $199.25 \pm 20.32^{\mathrm{A}}$ & $201.25 \pm 14.70^{\mathrm{A}}$ & $207.50 \pm 17.48^{\mathrm{A}}$ & $201.25 \pm 20.69^{\mathrm{A}}$ & $205.25 \pm 17.59^{\mathrm{A}}$ \\
& TL & $120.75 \pm 2.22^{\mathrm{B}}$ & $108.25 \pm 14.88^{\mathrm{Ba}}$ & $117.50 \pm 4.50^{\mathrm{B}}$ & $120.75 \pm 5.44^{\mathrm{B}}$ & $124.50 \pm 7.00^{\mathrm{B}}$ & $115.50 \pm 6.75^{\mathrm{B}}$ \\
& $\mathrm{C}$ & $88.00 \pm 6.82^{\mathrm{C}}$ & $84.13 \pm 11.22^{\mathrm{Bb}}$ & $85.25 \pm 8.39^{\mathrm{C}}$ & $87.00 \pm 9.31^{\mathrm{C}}$ & $90.50 \pm 7.33^{\mathrm{C}}$ & $85.13 \pm 7.20^{\mathrm{C}}$ \\
\hline \multirow{3}{*}{ ALB } & TH & $36.47 \pm 3.82$ & $31.80 \pm 4.92^{\mathrm{A}}$ & $33.05 \pm 3.79^{\mathrm{A}}$ & $34.63 \pm 3.63^{\mathrm{A}}$ & $34.20 \pm 5.26^{\mathrm{a}}$ & $34.00 \pm 4.22^{\mathrm{a}}$ \\
& TL & $38.05 \pm 0.88$ & $34.50 \pm 1.93$ & $36.38 \pm 1.48$ & $37.05 \pm 0.81$ & $38.25 \pm 1.35$ & $38.00 \pm 2.07^{\mathrm{b}}$ \\
& C & $38.48 \pm 2.09$ & $36.61 \pm 1.39^{\mathrm{B}}$ & $37.98 \pm 1.69^{\mathrm{B}}$ & $38.50 \pm 1.80^{\mathrm{B}}$ & $38.93 \pm 2.09^{\mathrm{b}}$ & $37.58 \pm 1.79^{\mathrm{b}}$ \\
\hline
\end{tabular}

Different capital letters in the same row represent a very significant difference $(P<0.01)$, different lowercase letters represent a significant difference $(0.01<P<0.05)$, and the same letter or without letters indicates no significant difference $(P>0.05)$.

Experimental cow insulin resistance status

As shown in Table 2, the concentration of blood glucose in the TL group was significantly lower than that of the other two groups, at $15 \mathrm{~min}$. But at 15-120 min, the TH group was significantly higher than the group TL and C; in a 15-90 min period, the concentration of plasma glucagon in the TL group was higher than Group C and TH. The plasma ADP concentration of the TH group was significantly lower than Group C in a $60-120$ min period.

Table 2. Glucose tolerance test and insulin resistance of dairy cows with ketosis.

\begin{tabular}{|c|c|c|c|c|c|c|c|}
\hline \multirow{2}{*}{ Parameter } & \multirow{2}{*}{ Group } & \multicolumn{6}{|c|}{ Administration of Glucose (Min) } \\
\hline & & -15 & 0 & 15 & 30 & 60 & 90 \\
\hline \multirow{3}{*}{ GLU } & $\mathrm{TH}$ & $3.53 \pm 1.06 \mathrm{~A}$ & $20.47 \pm 2.67$ & $14.87 \pm 0.79 \mathrm{a}$ & $11.63 \pm 0.58 \mathrm{~A}$ & $8.09 \pm 0.94 \mathrm{~A}$ & $5.42 \pm 1.24 \mathrm{~A}$ \\
\hline & $\mathrm{TL}$ & $2.00 \pm 0.45 \mathrm{~B}$ & $16.35 \pm 2.78$ & $11.90 \pm 1.41 b$ & $8.70 \pm 1.56 \mathrm{~B}$ & $5.49 \pm 0.38 \mathrm{~B}$ & $4.02 \pm 0.47 \mathrm{~B}$ \\
\hline & $\mathrm{C}$ & $3.18 \pm 0.42 \mathrm{~A}$ & $17.31 \pm 3.15$ & $12.18 \pm 2.43 b$ & $8.78 \pm 1.36 \mathrm{~B}$ & $5.53 \pm 0.93 \mathrm{~B}$ & $3.82 \pm 0.55 \mathrm{~B}$ \\
\hline \multirow{3}{*}{ GC } & $\mathrm{TH}$ & $358.97 \pm 6.99 \mathrm{~A}$ & $314.51 \pm 8.95 \mathrm{~A}$ & $332.86 \pm 8.34 \mathrm{a}$ & $361.67 \pm 32.67 \mathrm{Aa}$ & $343.72 \pm 9.27 \mathrm{~A}$ & $323.93 \pm 10.97 \mathrm{~A}$ \\
\hline & $\mathrm{TL}$ & $389.17 \pm 9.10 \mathrm{~B}$ & $355.77 \pm 18.32 \mathrm{~B}$ & $380.01 \pm 44.67 \mathrm{~b}$ & $418.48 \pm 7.88 \mathrm{~B}$ & $403.63 \pm 9.24 \mathrm{~B}$ & $364.78 \pm 6.52 \mathrm{~B}$ \\
\hline & $\mathrm{C}$ & $365.98 \pm 9.98 \mathrm{~A}$ & $323.18 \pm 8.90 \mathrm{~A}$ & $350.23 \pm 31.28$ & $385.92 \pm 6.29 \mathrm{Ab}$ & $351.25 \pm 11.05 \mathrm{~A}$ & $339.45 \pm 17.23 \mathrm{~A}$ \\
\hline \multirow{3}{*}{ INS } & $\mathrm{TH}$ & $7.42 \pm 0.11 \mathrm{~A}$ & $8.18 \pm 0.07 \mathrm{~A}$ & $8.75 \pm 0.77 \mathrm{~A}$ & $8.12 \pm 0.05 \mathrm{~A}$ & $7.65 \pm 0.34 \mathrm{~A}$ & $7.28 \pm 0.21 \mathrm{~A}$ \\
\hline & $\mathrm{TL}$ & $6.54 \pm 0.21 \mathrm{~B}$ & $7.65 \pm 0.04 \mathrm{~B}$ & $7.82 \pm 0.07 \mathrm{~B}$ & $7.20 \pm 0.04 \mathrm{~B}$ & $6.74 \pm 0.10 \mathrm{~B}$ & $6.29 \pm 0.27 \mathrm{Bb}$ \\
\hline & $\mathrm{C}$ & $6.53 \pm 0.22 \mathrm{~B}$ & $7.62 \pm 0.15 B$ & $7.84 \pm 0.14 \mathrm{~B}$ & $6.97 \pm 0.13 \mathrm{C}$ & $6.51 \pm 0.26 \mathrm{~B}$ & $6.65 \pm 0.25 a$ \\
\hline \multirow{3}{*}{ NEFA } & $\mathrm{TH}$ & $1.34 \pm 0.26 \mathrm{~A}$ & $0.91 \pm 0.02 \mathrm{Aa}$ & $0.94 \pm 0.03 \mathrm{~A}$ & $0.91 \pm 0.07 \mathrm{~A}$ & $0.98 \pm 0.14 \mathrm{~A}$ & $0.87 \pm 0.07 \mathrm{~A}$ \\
\hline & $\mathrm{TL}$ & $1.17 \pm 0.12 \mathrm{~A}$ & $0.78 \pm 0.02 \mathrm{Ab}$ & $0.79 \pm 0.02 \mathrm{Ba}$ & $0.78 \pm 0.06 \mathrm{Ba}$ & $0.83 \pm 0.06$ & $0.78 \pm 0.04 a$ \\
\hline & $\mathrm{C}$ & $0.67 \pm 0.09 \mathrm{~B}$ & $0.56 \pm 0.12 B$ & $0.68 \pm 0.08 \mathrm{Bb}$ & $0.68 \pm 0.03 \mathrm{Bb}$ & $0.70 \pm 0.08 \mathrm{~B}$ & $0.66 \pm 0.06 \mathrm{Bb}$ \\
\hline \multirow{3}{*}{ RQUICKI } & $\mathrm{TH}$ & $0.36 \pm 0.02 \mathrm{~A}$ & $0.29 \pm 0.01 \mathrm{~A}$ & $0.30 \pm 0.01 \mathrm{~A}$ & $0.31 \pm 0.01 \mathrm{~A}$ & $0.33 \pm 0.01 \mathrm{~A}$ & $0.36 \pm 0.01 \mathrm{~A}$ \\
\hline & $\mathrm{TL}$ & $0.41 \pm 0.02 \mathrm{~B}$ & $0.31 \pm 0.01$ & $0.32 \pm 0.01 \mathrm{~B}$ & $0.34 \pm 0.01 B$ & $0.36 \pm 0.01 \mathrm{~B}$ & $0.39 \pm 0.01 \mathrm{~B}$ \\
\hline & $\mathrm{C}$ & $0.42 \pm 0.01 \mathrm{~B}$ & $0.32 \pm 0.02 B$ & $0.33 \pm 0.01 \mathrm{~B}$ & $0.35 \pm 0.01 \mathrm{~B}$ & $0.37 \pm 0.01 \mathrm{~B}$ & $0.40 \pm 0.01 \mathrm{~B}$ \\
\hline \multirow{3}{*}{ BHBA } & $\mathrm{TH}$ & $3.54 \pm 1.56 \mathrm{~A}$ & $3.07 \pm 1.56 \mathrm{Aa}$ & $2.62 \pm 1.64 \mathrm{~A}$ & $2.13 \pm 1.79 \mathrm{~A}$ & $1.86 \pm 1.46 \mathrm{~A}$ & $1.61 \pm 1.12 \mathrm{~A}$ \\
\hline & $\mathrm{TL}$ & $2.64 \pm 0.63 \mathrm{~A}$ & $1.67 \pm 0.66 b$ & $1.40 \pm 0.66$ & $0.94 \pm 0.44$ & $0.81 \pm 0.48$ & $0.94 \pm 0.29$ \\
\hline & $\mathrm{C}$ & $0.80 \pm 0.21 \mathrm{~B}$ & $0.62 \pm 0.23 \mathrm{~B}$ & $0.51 \pm 0.17 \mathrm{~B}$ & $0.41 \pm 0.22 \mathrm{~B}$ & $0.40 \pm 0.04 \mathrm{~B}$ & $0.42 \pm 0.17 \mathrm{~B}$ \\
\hline \multirow{3}{*}{$\mathrm{ADP}$} & $\mathrm{TH}$ & $257.94 \pm 16.02$ & $267.19 \pm 2.09$ & $255.51 \pm 26.10$ & $264.24 \pm 34.39$ & $260.84 \pm 11.76 \mathrm{a}$ & $256.65 \pm 2.42 \mathrm{a}$ \\
\hline & $\mathrm{TL}$ & $270.04 \pm 4.35$ & $273.96 \pm 13.30$ & $267.30 \pm 12.86$ & $274.91 \pm 2.31$ & $274.00 \pm 4.28$ & $264.23 \pm 8.18 b$ \\
\hline & $\mathrm{C}$ & $271.96 \pm 19.05$ & $276.51 \pm 17.45$ & $266.75 \pm 21.16$ & $270.90 \pm 9.19$ & $268.98 \pm 8.19 b$ & $264.42 \pm 3.28 b$ \\
\hline
\end{tabular}

Different capital letters at the same time represent a highly significant difference $(P<0.01)$, different lowercase letters represent a significant difference $(0.01<P<0.05)$, and the same letter or without letters indicate no significant difference $(P>0.05)$. 
At all time periods, the concentration of insulin in Group TH was significantly higher than the other two groups; the NEFA concentration in Group C was lower than the other two groups; the plasma insulin sensitivity index of group TH was significantly lower than Group TL and C, and the BHBA concentration in the TH group was higher than that in Group C.

The above results indicate a disorder of glucose metabolism in the TH group, abnormal glucose tolerance and hyperinsulinemia occur in diseased cows, which also have severe IR. The rate of BHBA decrease in the TH group was lower than that in the TL group after carbohydrate supplementation, indicating this process was not effective in reducing the concentration of BHBA in the TH group. The concentration of BHBA in the TH group increased and ADP concentrations decreased, indicating a negative energy balance and a decline in ability to antagonize insulin resistance.

\section{Oxidative stress conditions of experimental cows}

As shown in Table 3, at almost all time points, the SOD content of the TH group was significantly lower than that of the other two groups the T-AOC concentrations in $\mathrm{C}$ group was remarkably higher than those in Group TH and TL, and the MDA in the $\mathrm{C}$ group was significantly lower than that of the other two groups.

The above results showed that the antioxidant capacity of the TH cows with ketosis declined and the activity of the oxidative system was enhanced, the body was in a state of oxidative stress. The antioxidant system and oxidative system of the TL cows basically maintained a balance, and no obvious oxidative stress was observed.

Table 3. Changes of the oxidative stress in dairy cows with ketosis during the glucose tolerance test.

\begin{tabular}{cccccccc}
\hline \multirow{2}{*}{ Parameter } & \multirow{2}{*}{ Group } & \multicolumn{5}{c}{ Administration of Glucose (Min) } \\
\cline { 2 - 8 } & & -15 & 0 & 15 & 30 & 60 & 90 \\
\hline \multirow{2}{*}{ SOD } & TH & $46.30 \pm 3.03 \mathrm{~A}$ & $46.84 \pm 2.63$ & $46.28 \pm 2.83 \mathrm{~A}$ & $45.10 \pm 3.13 \mathrm{a}$ & $45.53 \pm 3.42 \mathrm{~A}$ & $45.32 \pm 3.13 \mathrm{a}$ \\
& TL & $55.02 \pm 3.50 \mathrm{~B}$ & $51.66 \pm 3.67$ & $54.53 \pm 1.61 \mathrm{~B}$ & $53.15 \pm 3.73 \mathrm{~b}$ & $49.30 \pm 2.00 \mathrm{a}$ & $48.69 \pm 2.29$ \\
& $\mathrm{C}$ & $55.75 \pm 3.48 \mathrm{~B}$ & $50.76 \pm 6.58$ & $53.36 \pm 4.33 \mathrm{~B}$ & $52.62 \pm 5.15 \mathrm{~b}$ & $53.64 \pm 3.00 \mathrm{Bb}$ & $52.94 \pm 6.47 \mathrm{~b}$ \\
\hline \multirow{2}{*}{ T-AOC } & TH & $3.23 \pm 0.09 \mathrm{~A}$ & $3.17 \pm 0.07 \mathrm{~A}$ & $3.17 \pm 0.08 \mathrm{~A}$ & $3.16 \pm 0.09 \mathrm{Aa}$ & $3.12 \pm 0.09 \mathrm{~A}$ & $3.04 \pm 0.07 \mathrm{a}$ \\
& TL & $3.42 \pm 0.08 \mathrm{a}$ & $3.34 \pm 0.17 \mathrm{~A}$ & $3.34 \pm 0.06 \mathrm{~A}$ & $3.31 \pm 0.05 \mathrm{Ab}$ & $3.24 \pm 0.28$ & $3.31 \pm 0.44$ \\
& $\mathrm{C}$ & $3.70 \pm 0.24 \mathrm{Bb}$ & $3.67 \pm 0.18 \mathrm{~B}$ & $3.64 \pm 0.19 \mathrm{~B}$ & $3.72 \pm 0.08 \mathrm{~B}$ & $3.47 \pm 0.30$ & $3.52 \pm 0.33 \mathrm{~b}$ \\
\hline \multirow{3}{*}{ MDA } & TH & $2.67 \pm 0.15 \mathrm{~A}$ & $2.86 \pm 0.03 \mathrm{~A}$ & $2.53 \pm 0.15 \mathrm{~A}$ & $2.42 \pm 0.32 \mathrm{a}$ & $2.45 \pm 0.29 \mathrm{~A}$ & $2.33 \pm 0.12 \mathrm{~A}$ \\
& TL & $2.33 \pm 0.11 \mathrm{Ba}$ & $2.58 \pm 0.09 \mathrm{~B}$ & $2.34 \pm 0.22 \mathrm{a}$ & $2.29 \pm 0.04$ & $2.41 \pm 0.25 \mathrm{~A}$ & $2.18 \pm 0.11 \mathrm{~A}$ \\
& $\mathrm{C}$ & $2.16 \pm 0.07 \mathrm{Bb}$ & $2.10 \pm 0.06 \mathrm{C}$ & $2.09 \pm 0.08 \mathrm{Bb}$ & $2.08 \pm 0.09 \mathrm{~b}$ & $1.99 \pm 0.09 \mathrm{~B}$ & $2.05 \pm 0.13 \mathrm{~B}$ \\
\hline
\end{tabular}

Different capital letters in the same row represent a very significant difference $(P<0.01)$, different lowercase letters represent a significant difference $(0.01<P<0.05)$, and the same letter or without letters indicates no significant difference $(P>0.05)$.

\section{DISCUSSION}

\section{The liver function of cows with type II ketosis}

Type I ketosis is a spontaneous disease which occurs in cows, three to six weeks after calf delivery. The biochemical nature of the disease is characterized by ketone bodies and increased NEFA, insulin and decreased Glu. Due to increased lactation after delivery and reduced DMI at the beginning of labor, this leads to a negative energy balance (NEB) [27]. Glu concentrations are reduced as intensified body fat mobilization leads to increased ketone bodies [15]. If NEB is not relieved, cows get ketosis.

In contrast, type II ketosis usually occurs one to two weeks after calf delivery Biochemically, it is char- acterized as elevated ketone bodies, insulin, and NEFA and high or normal Glu levels. Overfeeding animals during dry periods can lead to prenatal obesity. Obesity leads to decreased insulin sensitivity and blood glucose utilization. Excess glucose continuously stimulates islet cells to secrete high levels of insulin and blood sugars, causing insulin levels to increase. Excess glucose is converted to hepatic and muscle glycogen, which is further converted to glucose when blood glucose levels are lowered [23]. However, when glycogen storage reaches its upper limit, excess glucose is converted to fat and stored in liver cells. These cells perform fat mobilization and gluconeogenesis to remove excess fat. However, gluconeogenesis leads to an increase in glucose content, therefore the concentration of Glu in 
type II ketosis cows does not decrease. When fat storage exceeds the clearance ability of liver cells, it causes fat accumulation in liver cells leading to liver damage. Part of the fat is transferred to the skin (e.g. the abdomen, chest, back, armpits and buttocks), promoting obesity.

ALT and AST are typical indicators of liver damage. ALT is a main indicator of hepatocyte integrity and is also a sensitive indicator of acute hepatitis which is mainly stored in the cytoplasm of hepatocytes.Under normal circumstances, the blood contains reduced AST, however when the liver is damaged, blood levels of AST increase and ALB synthesis decreases [3,13].In this study, liver function damage in cow, with abnormal glucose tolerance is more serious. The liver is an important organ for glucose metabolism and liver damage can lead to disorders of glucose metabolism, which in turn lead to a negative energy balance. When a cow's body energy is insufficient, the liver converts fat into energy for utilization under certain conditions [13]. However, the liver's ability to convert fat into glucose is limited [19]. When the body's fat metabolism is excessive, the liver proceeds to ketone formation [24]. Although ketone bodies provide energy in the absence of sugars, energy supply efficiency is low, causing metabolic acidosis in dairy cows, leading to a vicious cycle of ketosis and acidosis. Increasing the load on liver function can cause different degrees of damage to the organ. The basic lesion of type II ketosis is a fatty liver. During dairy cows'duration of parturition, fat infiltration occurs at the liver and insulin resistance occurs after calving. In addition, the liver contains more insulin receptors, therefore when liver cells are damaged insulin action is weakened and the body exhibits different degrees of insulin resistance. IR prevents blood sugar entry into cells for homeostatic functions. Disorders of glucose metabolism are caused by impaired liver function and are related to insulin resistance. Such disorders are important factor in promoting ketosis.

\section{Insulin resistance status of type II ketosis in cows}

When an animal's body has an energy metabolism disorder under high blood sugar levels, glucose utilization rates decrease, indicating abnormal glucose tolerance has occurred [23].Insulin is a hypoglycemic hormone which is antagonistic to glucagon. In this experiment, insulin concentrations and blood glucose concentrations of $\mathrm{TH}$ groups were significantly higher than those of the other two groups, and the concentration of glucagon was lower than that of TL group. The plasma RQUICKI level was significantly lower than that of the TL and C group.
Insulin is a hypoglycemic hormone which is antagonistic to glucagon. When glucose tolerance is impaired, the body's insulin sensitivity is reduced. The insulin sensitivity index is a key indicator determining whether the body has developed insulin resistance. The index indicates that insulin resistance occurs in ketosis cows with abnormal glucose tolerance. Excessive release of insulin increases fatty acid synthase activity [20].Increased synthesis of fatty acids increases body weight and also increases insulin resistance. Negative energy balance, due to lactation, abnormal glucose tolerance and stress also enhances body fat mobilization, resulting in elevated NEFA levels. NEFA is not completely oxidized to produce ketone bodies.

BHBA levels in serum is the gold standard for the diagnosis of cow ketosis [25]. BHBA is more stable in the blood than acetone or acetoacetate [15].The most commonly used threshold is serum BHBA $\geq 1400 \mu \mathrm{mol} / \mathrm{L}$ [5], and some studies have used $1200 \mu \mathrm{mol} / \mathrm{L}$ as a threshold [21]. However, the critical value chosen usually has only a minor effect on group-based studies and clinical ketosis is usually associated with higher levels of BHBA [31] (e.g. $3000 \mu \mathrm{mol} / \mathrm{L}$ or higher). The concentration of NEFA and BHBA in the blood is a sign of negative energy balance [9].The concentration of BHBA and NEFA in the $\mathrm{TH}$ group was significantly higher than in the group $\mathrm{C}$, and the concentration of BHBA was higher than the critical value of ketosis. It can be seen there was a negative energy balance in ketosis cows with abnormal glucose tolerance. Adiponectin is an adipocytokine secreted by adipocytes, involved in fat metabolism, maintains energy balance, regulates insulin sensitivity [30], and antagonizes IR. Studies have shown that ADP levels are significantly decreased in patients with early insulin resistance, ADP content is negatively correlated with insulin resistance, and positively correlated with insulin sensitivity index [28], and its level has an early warning effect on insulin resistance [6]. Therefore, it is clinically possible to monitor the occurrence and development of insulin resistance by detecting the content of adiponectin. However, the ADP content in the TH group was lower than the other two groups at all time-points. There was no significant difference between the three groups, which is worth further investigation.

\section{Oxidative stress in cows with type II ketosis}

When the body's antioxidant system, which removes peroxide is out of balance with peroxide generation, the body is in an oxidative damage state. SOD is a metal antioxidant enzyme and its level are key indicators in measuring the removal of oxidizing substances. 
T-AOC is a measuring indicator for total antioxidant function [7,12]. In this study, the reduction of SOD and $\mathrm{T}$-AOC concentrations in the $\mathrm{TH}$ group indicated that the antioxidant capacity of ketone cows with abnormal glucose tolerance was reduced. These cows were in an oxidative stress state, which may be the main cause of blood glucose metabolism disorder [10]. MDA is an intermediate product of lipid metabolism and is a key indicator of measuring lipid oxidation, which can indirectly reflect the degree of damage to cells [12]. In this study, the concentration of MDA in the TH group increased and the body's oxidative capacity increased.

Oxidative stress can stimulate the body to produce IR. Studies on the indicators of glucose tolerance and oxidative stress in ketosis cows have indicated that the balance between the body's oxidation systems and antioxidant systems is broken, and that ketosis cows with abnormal glucose tolerances, are in a state of severe oxidative stress and insulin resistance. Their blood glucose concentrations are well maintained, but cows are still in a negative energy balance, causing type II ketosis.

\section{CONCLUSIONS}

The glucose tolerance test can effectively assess the presence of insulin resistance and show that type II ketosis occurs in dairy cows. Such ketosis suggests disorders in the utilization of body sugar, which is closely related to insulin resistance. The disorder can be attributed to abnormal liver function and oxidative stress.

\section{MANUFACTURERS}

${ }^{1}$ Beijing Jiuliang Company. Bei Jing, China.

${ }^{2}$ Biosino Bio-Technology and Science Incorporation. Bei Jing, China.

${ }^{3}$ Nanjing Jiancheng Institute of Biology. Nan Jing, China.

${ }^{4}$ Japan Sekisui Science and Technology Co. Ltd. Tokyo, Japan.

${ }^{5}$ RD Company. Park Rapids, MN, USA.

${ }^{6}$ Hitachi. Tokyo, Japan.

${ }^{7}$ Shanghai Precision. Shanghai, China.

${ }^{8}$ East China electronic. Nanjing, China.

Funding. National Science and Technology Project of the Twelfth Five-Year Plan (2013BAD21B01-2, 2012BAD12B05-2 and 2012BAD12B03-2). Screening and confirmation of serum biomarkers for subclinical vitamin E deficiency in early lactation high-yielding dairy cows. Daqing 163319, China. (31873028).

Acknowledgements. This work was funded by Heilongjiang Province Applied Technology Research and Development Plan Major Project (GA16B202) and Standardized breeding industry demonstration project for poverty reduction (ZY17C08). The authors thanks lab-mates for collecting samples, the guidance of the teacher, and all those who contributed to the paper.

Declaration of interest. The authors report no conflicts of interest. The authors alone are responsible for the content and writing of the paper.

\section{REFERENCES}

1 Abuelo A., Hernández J., Benedito J.L. \& Castillo C. 2016. Association of oxidative status and insulin sensitivity in periparturient dairy cattle: an observational study. Journal of Animal Physiology and Animal Nutrition. 100(2): 279286.

2 Balogh O., Szepes O., Kovacs K., Kulcsar M., Reiczigel J., Alcazar J.A., Keresztes M., Febel H., Bartyik J., Fekete S.G., Fesus L. \& Huszenicza G. 2008. Interrelationships of growth hormone alui polymorphism, insulin resistance, milk production and reproductive performance in holstein-friesian cows. Veterinarni Medicina - UZPI. 53(11): 604616.

3 Bobe G., Young J.W. \& Beitz D.C. 2004. Invited review: pathology, etiology, prevention, and treatment of fatty liver in dairy cows. Journal of Dairy Science. 87(10): 3105-3124.

4 Bourahalfon S. \& Zick Y. 2009. Phosphorylation of irs proteins, insulin action, and insulin resistance. American Journal of Physiology-Endocrinology and Metabolism. 296(4): E581-591.

5 Carrier J., Godden S., Fetrow J. \& Rapnicki P. 2004. Evaluation and use of three cowside tests for detection of subclinical ketosis in early postpartum cows. Journal of Dairy Science. 87(11): 3725-3735.

6 Chen H., Montagnani M., Funahashi T., Shimomura I. \& Quon M.J. 2003. Adiponectin stimulates production of nitric oxide in vascular endothelial cells. Journal of Biological Chemistry. 278(45): 45021-45026.

7 Cheng J., Zheng N., Sun X., Li S., Wang J. \& Zhang Y. 2016. Feeding rumen-protected gamma-aminobutyric acid enhances the immune response and antioxidant status of heat-stressed lactating dairy cows. Journal of Thermal Biology. 60: 103-108. 
8 De Koster J.D. \& Opsomer G. 2013. Insulin resistance in dairy cows. Veterinary Clinics of North America Food Animal Practice. 29(2): 299-322.

9 Djoković R., Cincović M., Belić B., Toholj B., Davidov I. \& Hristovska T. 2015. Relationship between blood metabolic hormones, metabolites and energy balance in Simmental dairy cows during peripartum period and lactation. Pakistan Veterinary Journal. 35(2): 163-167.

10 Du X., Chen L., Huang D., Peng Z., Zhao C. \& Zhang Y. 2017. Elevated apoptosis in the liver of dairy cows with ketosis. Journal of Experimental Cellular Physiology Biochemistry \& Pharmacology. 43(2): 568-573.

11 Gallagher D., Kelley D.E., Yim J.E., Spence N., Albu J., Boxt L., Xavier P. S., Pi-Sunyer F. X., Heshka S. \& The MRI Ancillary Study Group of the Look AHEAD Research Group. 2009. Adipose tissue distribution is different in type 2 diabetes. American Journal of Clinical Nutrition. 89(3): 807-814.

12 Gong J. \& Xiao M. 2018. Effect of Organic Selenium Supplementation on Selenium Status, Oxidative Stress, and Antioxidant Status in Selenium-Adequate Dairy Cows During the Periparturient Period. Biological Trace Element Research. 186(2): 430-440.

13 González F.D., Muiño R., Pereira V., Campos R. \& Benedito J.L. 2011. Relationship among blood indicators of lipomobilization and hepatic function during early lactation in high-yielding dairy cows. Journal of Veterinary Science. 12(3): 251-255.

14 Herdt T.H. 2000. Ruminant adaptation to negative energy balance. influences on the etiology of ketosis and fatty liver. Veterinary Clinics of North America Food Animal Practice. 16(2): 215-230.

15 Herdt T.H. 2000. Variability characteristics and test selection in herdlevel nutritional and metabolic profile testing: Metabolic disorders of ruminants. Veterinary Clinics of North America: Food Animal Practice. 16(2): 387-403.

16 Holtenius P. \& Holtenius K. 2007. A model to estimate insulin sensitivity in dairy cows. Acta Veterinaria Scandinavica. 49(1): 29-31.

17 Holtenius P. \& Holtenius K. 2010. New aspects of ketone bodies in energy metabolism of dairy cows: a review. Zentralblatt Für Veterinärmedizin Reihe A. 43(1-10): 579-587.

18 Hutley L. \& Prins J.B. 2005. Fat as endocrine organ: relationship to the metabolic syndrome. The American Journal of the Medical Sciences. 330(6): 280-289.

19 Imhasly S., Naegeli H., Baumann S., von Bergen M., Luch A., Jungnickel H., Potratz S. \& Gerspach C. 2014. Metabolomic biomarkers correlating with hepatic lipidosis in dairy cows. BMC Veterinary Research. 10(1): 1-9.

20 Li P., Li X.B., Fu S.X., Wu C.C., Wang X.X. \& Yu G.J. 2012. Alterations of fatty acid $\beta$-oxidation capability in the liver of ketotic cows. Journal of Dairy Science. 95(4): 1759-1766.

21 McArt J.A.A., Nydam D.V. \& Oetzel G.R. 2012. Epidemiology of subclinical ketosis in early lactation dairy cattle. Journal of Dairy Science. 95(9): 5056-5066.

22 Muniyappa R., Lee S., Chen H. \& Quon M.J. 2008. Current approaches for assessing insulin sensitivity and resistance in vivo: advantages, limitations, and appropriate usage. American Journal of Physiology-Endocrinology and Metabolism. 294(1): E15-26.

23 Nwose O.M. \& Jones M.R. 2013. Atypical mechanism of glucose modulation by colesevelam in patients with type 2 diabetes. Clinical Medicine Insights: Endocrinology and Diabetes. 6(6): 75-79.

24 Ospina P.A., Mcart J.A., Overton T.R., Stokol T. \& Nydam D.V. 2013. Using nonesterified fatty acids and $\beta$-hydroxybutyrate concentrations during the transition period for herd-level monitoring of increased risk of disease and decreased reproductive and milking performance. Veterinary Clinics of North America Food Animal Practice. 29(2): 387-412.

25 Padilla L., Shibano K. \& Inoue J. 2005. Plasma vitamin c concentration is not related to the incidence of ketosis in dairy cows during the early lactation period. Journal of Veterinary Medical Science. 67(9): 883-886.

26 Sundrum A. 2015. Metabolic disorders in the transition period indicate that the dairy cows'ability to adapt is overstressed. Animals: An Open Access Journal from MDPI. 5(4): 978-1020.

27 Suthar V.S., Canelas-Raposo J., Deniz A. \& Heuwieser W. 2013. Prevalence of subclinical ketosis and relationships with postpartum diseases in European dairy cows. Journal of Dairy Science. 96(5): 2925-2938.

28 Weyer C., Funahashi T., Tanaka S., Hotta K., Matsuzawa Y., Pratley R.E. \& Tataranni P.A. 2001. Hypoadiponectimia in obesity and type 2 diabetes: close association with insulin resistance and hyperinsulinemia. Journal of Clinical Endocrinology \& Metabolism. 86(3): 1930-1935. 
29 Xu C., Shu S., Xia C., Wang B. \& Zhang H.Y. 2014. Investigation on the Relationship of Insulin Resistance and Ketosis in Dairy Cows. Journal of Veterinary Science Technology. 05(2): 162-165.

30 Yamauchi T. \& Kadowaki T. 2008. Physiological and pathophysiological roles of adiponectin and adiponectin receptors in the integrated regulation of metabolic and cardiovascular diseases. International Journal of Obesity. 32(Suppl 7): S13.

31 Youssef M. \& El-Ashker M. 2017. Significance of insulin resistance and oxidative stress in dairy cattle with subclinical ketosis during the transition period. Tropical Animal Health \& Production. 49(2): 239-244. 